\title{
ORMEÑO, J. \& VATTER, M. (EDS.). FORZADOS A SER LIBRES. KANT Y LA TEORIAA REPUBLICANA DEL DERECHO. 246 PÁGS. SANTIAGO DE CHILE, 2017: FONDO DE CULTURA ECONÓMICA
}

\author{
Martín Ignacio Molina Suárez \\ Pontificia Universidad Católica de Chile
}

Puede considerarse superada, gracias a serias investigaciones modernas, la deletérea crítica que algunos estudiosos hicieron en el pasado en contra de la doctrina kantiana del derecho, recogida especialmente en La Metafísica de las Costumbres (Die Metaphysik der Sitten, 1797). La obra conjunta, materia de reseña, editada por los profesores Juan Ormeño y Miguel Vatter, puede considerarse un ejemplo de dicha superación y, más aún, el fruto de una seria investigación sobre el pensamiento kantiano en torno al derecho, con gran beneficio para el público de habla española.

Como se afirma en la "Introducción" a cargo de los editores, el objeto común de los ensayos reunidos en el libro se manifiesta en un aspecto general, a saber, ofrecer una introducción a la Doctrina del derecho de Kant y, en uno particular, consistente en "dirimir la cuestión de la afiliación política del pensamiento kantiano" (p. 13), relacionándolo con los debates actuales. La división del libro en cuatro partes parece cumplir de buena manera con aquello que se pretende; en efecto, la primera de ellas desarrolla, en dos diferentes ensayos, el problema de la aplicación en un futuro sistema político de la Ley moral descubierta en la Fundamentación para una metafísica de las costumbres. La segunda parte del libro se hace cargo, a su vez, de la tradicional opinión que afirma la fundamentación de la Doctrina del derecho de Kant en su teoría moral; los autores de los dos ensayos que recoge esta parte comparten una posición contraria a la tradición. La tercera parte de la obra, que agrupa tres ensayos, está dedicada a la investigación de la noción de libertad que está incluida y que forma parte esencial del concepto de derecho en Kant. La última parte, que recoge los últimos dos ensayos del libro, se ocupa de la relación entre una doble -y clásica- distinción del derecho, a saber, el natural y el privado, el civil y el público. Finaliza esta obra con la inclusión de la bibliografía empleada por los autores en sus ensayos, aunque se echa de menos la inserción de una bibliografía especializada sobre la señalada doctrina del derecho que incluya, por ejemplo, el indispensable comentario de B. Scharon Byrd y Joachim Hruschka sobre la materia (Kant's Doctrine of Right).

\footnotetext{
${ }^{1}$ Programa de Licenciatura en Filosofía. E-mail: mimolina2@uc.cl.
} 
El primer ensayo, titulado "Siete pecados capitales kantianos" (pp. 25-45), del profesor Ernesto Garzón Valdés, ofrece un listado que recoge algunos atentados contra el derecho nacional e internacional, que son analizados - por supuesto- a la luz del pensamiento kantiano. Los pecados son los que siguen: "la creencia en la naturaleza angélica del hombre, el condicionamiento de la voluntad por condiciones de la felicidad, la violación del principio de publicidad de las leyes, la intervención en los asuntos internos de los Estados, el colonialismo, la imposición de una autoridad mundial suprema, la guerra" (p. 25). Es destacable el tratamiento del cuarto pecado a partir de la analogía entre Estado y persona, así como lo es la propuesta de paz republicana a partir de la afirmación de la dignidad humana que se ofrece como remedio al pecado de la guerra.

El profesor Juan Manuel Garrido desarrolla en el segundo ensayo, titulado "¿Y si la vida no fuera un derecho? Ser vivo e ius necessitatis" (pp. 47-64), la idea de la propiedad o derecho que pueda tener una vida por sí misma, a partir del derecho a eximirse de toda responsabilidad penal en beneficio de la propia vida y de su integridad física (derecho de necesidad). Esta idea, empero, resulta opuesta a la postura de Kant, para quien el derecho de necesidad está excluido del ámbito jurídico, de manera que solo la persona (y no la vida) es sujeto de derechos. Esto constituye, conforme a la tesis del autor, una novedad respecto de la noción tradicional de la vida como autoapropiación. Resulta especialmente interesante la comparación que se hace entre la postura kantiana y las de Fichte y Hegel; este último, por cierto, incorpora al estado de necesidad en el orden jurídico, en franca oposición a Kant.

El tercer capítulo del libro, “¿Qué es erróneo en una interpretación moral de la filosofía política de Kant?” (pp. 67-96), del profesor Christoph Horn (trad. Juan Ormeño), contiene una crítica a la postura tradicional (afirmada, entre otros, por Höffe, Herb y Ludwig) conforme a la cual se afirma que la Doctrina del derecho de Kant está fundada en el imperativo categórico, de manera tal que las leyes morales serían las condiciones de su filosofía política y jurídica. Para Horn, no existe algo así como un "imperativo categórico del derecho" ni admite equivalentes de este ( $p$. 91), algo que ofrece demostrar a partir de un detallado análisis de las fuentes, de una interpretación kantiana de la teoría contractualista, y de la teoría de la propiedad desarrollada por Kant en su Metafisica de las costumbres.

La misma tesis desarrolla el profesor Marcus Willaschek (trad. Nicolás Vargas) en su ensayo titulado "Derecho y coacción. ¿Puede derivarse la concepción del derecho de Kant de su teoría moral?” (pp. 97-128), aunque desde un enfoque distinto al de Horn. En efecto, el autor se sirve de la identificación entre derecho y coacción para descartar la derivación de la Doctrina del derecho a partir del imperativo categórico. Resulta también digno de atención el tratamiento 
crítico que Willaschek hace de la ingeniosa solución propuesta por Paul Guyer consistente en establecer el fundamento del derecho a partir de la distinción entre libertad externa e interna.

El capítulo quinto de la obra, titulado "A propósito de finalidad y formalidad en la formulación del imperativo categórico kantiano" (pp. 129142), del profesor Nicolás Vargas Carlier, ofrece, a diferencia de los dos ensayos anteriores, una conexión entre la Doctrina del derecho y el imperativo categórico, a partir del contenido del que dota a esta última consistente en un sentimiento íntimo o deseo en su formulación. De esta guisa, el autor postula una conexión complementaria entre la Fundamentación, la Crítica de la razón práctica y la Metafísica de las costumbres.

El sexto ensayo del libro, obra del profesor Eduardo Molina Cantó, titulado "Libertad y exterioridad” (pp. 145-157), pretende establecer una conexión entre la noción de libertad interior (referida al actuar moral posible de una voluntad no coaccionada) y libertad exterior (referida a la coacción propia del derecho) presente en la Doctrina del derecho. Además, el autor desarrolla las cinco diferentes nociones de libertad que están presentes en la obra de Kant, a saber, libertad empírica, libertad moral, libertad como espontaneidad, libertad en el sentido trascendental y libertad como postulado.

El papel desempeñado por los tres deberes jurídicos (vivir honestamente, no dañar al otro y dar a cada uno lo suyo) en la Doctrina del derecho de Kant es la principal ocupación del ensayo del profesor Juan Ormeño Karzulovic, titulado "Violencia y autorrespeto: las bases kantianas de la libertad exterior" (pp. 159-173). El autor centra especialmente su análisis en el primer deber jurídico, afirmando que la honestidad en el vivir es condición que hace posible la agencia jurídica, deber que -a su vez- es posible en virtud de la existencia de una comunidad o estado civil.

El capítulo octavo, "El derecho a tener derechos y las reglas de Ulpiano en la Doctrina del derecho kantiana" (pp. 175-194), escrito por el profesor Miguel Vatter, insiste en la doctrina de los deberes jurídicos; esta vez, se analiza la calidad de ciudadanía a partir de dichos deberes, concluyéndose que aquellos constituyen a esta en la medida en que su finalidad es la constitución civil. Para Vatter, la ciudadanía es un estatus cuya acción política debe ir más allá del ejercicio del derecho a voto, pues corresponde también al estatus de un pueblo que juzga a las instituciones y al gobierno mismo.

El noveno ensayo, titulado “Justificación normativa y justificación funcional de la necesidad del Estado en Kant” (pp. 197-208), del profesor Alessandro Pinzani, desarrolla la cuestión del exeundum e statu naturali, esto es, la cuestión de la justificación de la entrada al estado civil en desmedro del estado de naturaleza. El autor desarrolla una postura intermedia entre aquellos intérpretes que afirman una 
consonancia entre lo afirmado por Kant y pensadores como Hobbes y Locke (para quienes la garantía de la paz y la propiedad resultan fundamentales en la entrada al estado civil), y aquellos comentaristas que apartan a Kant de los mencionados filósofos, sosteniendo que este halla en la fundación del Estado una cuestión de progreso moral de la humanidad. Para Pinzani, el exeundum sería la condición necesaria para la realización de la libertad exterior.

El último capítulo del libro, titulado "Libertad y propiedad en la fundamentación del Estado y el cosmopolitismo kantiano" (pp. 209-231), escrito por el profesor Daniel Loewe, continúa con el tratamiento de la respuesta kantiana a la cuestión del exeundum, examinando, en primer lugar, los supuestos metafísicos a los que da lugar, considerando la necesidad del Estado para la posibilidad de la libertad y la propiedad, y, en segundo lugar, su manifestación en la relación entre el estado civil y el cosmopolitismo, la cual no parece contravenir -al menos, en el papel- la idea de una República de todos los ciudadanos del mundo.

En conclusión, los ensayos que recoge el volumen que se ha reseñado ofrecen una argumentación bien ponderada y actual sobre los aspectos más esenciales de la Doctrina del derecho de Kant. Más allá de las diferentes interpretaciones y tomas de posición que desarrollan cada uno de los autores, es perfectamente admisible calificar a la obra en su conjunto como una excelente introducción a la Doctrina del derecho kantiana en idioma español; en efecto, las posturas más importantes sobre ella, incluso las que se controvierten, son desarrolladas de manera completa. Valga, entonces, la recomendación de su lectura. 